\title{
Pain Management in a Parturient with Presacral Mass
}

\author{
Tan Yan Ru, John Paul Lew, Ong Yee Yian, Antonia Zeng \\ Singapore General Hospital, Singapore, Singapore \\ Email: tan.yan.ru@singhealth.com.sg, john.paul.lew.h.j@singhealth.com.sg, ong.yee.yian@singhealth.com.sg, \\ antonia.zeng.1@singhealth.com.sg
}

How to cite this paper: Ru, T.Y., Lew, J.P., Yian, O.Y. and Zeng, A. (2017) Pain Management in a Parturient with Presacral Mass. Open Journal of Anesthesiology, 7, 364-370.

https://doi.org/10.4236/ojanes.2017.711037

Received: October 19, 2017

Accepted: November 14, 2017

Published: November 17, 2017

Copyright $\odot 2017$ by authors and Scientific Research Publishing Inc.

This work is licensed under the Creative

Commons Attribution International

License (CC BY 4.0).

http://creativecommons.org/licenses/by/4.0/

\begin{abstract}
Presacral masses are rare lesions and due to obscure anatomic location and etiological heterogeneity, they pose a diagnostic and therapeutic challenge. Literature is limited on the pain management of a parturient with presacral mass. We describe here a parturient in her second trimester with severe pain from a presacral mass. A high clinical acumen with early multidisciplinary involvement are needed to establish a diagnosis and provide treatment options for the well-being of the patient, minimize fetal teratogenicity, avoid chronic symptoms and long-term disability.
\end{abstract}

\section{Keywords}

Presacral Mass, Pregnancy, Pain Management, Analgesics

\section{Introduction}

Management of acute pain in pregnancy is unique in the consideration for both mother and fetus. Most cases are approached by evaluating the cause of pain, ruling out an obstetric cause, then subsequently treated with common analgesics, rest, and providing education to the patient about pain and the effects on the fetus [1].

Presacral masses are rare lesions and due to obscure anatomic location, difficult surgical approach and etiological heterogeneity, they pose a diagnostic and therapeutic challenge [2] [3]. We describe here a case of a pregnant woman with a presacral mass, presenting with severe buttock pain during her second trimester.

\section{Case Report}

A 33-year-old Chinese female, Gravida 6 Para 1, was referred to us at 25 weeks 
of gestation for severe left buttock pain.

She first presented with left buttock pain at 13 weeks gestation. Magnetic Resonance Imaging (MRI) scan showed a $9.2 \mathrm{~cm} \times 5.7 \mathrm{~cm} \times 8.6 \mathrm{~cm}$ presacral mass with aggressive features. Malignancy was the primary consideration based on the MRI images. She was referred to our hospital for further management. An ultrasound guided biopsy of presacral mass was done and histology showed xanthogranulomatous inflammation with fibrosis. She was a smoker with previous illicit drug use of amphetamines and benzodiazepines (which she stopped during this pregnancy). She had a previous caesarean section 8 years ago. Her management was discussed at tumour board meeting and the recommendation was for interval surveillance scans as patient was not keen for any intervention. Meanwhile she was treated with oral analgesics with paracetamol, naproxen, and tramadol.

She was admitted at 25 weeks gestation, for worsening left buttock pain. Her pain score was 10/10 at rest and at movement, and she was unable to ambulate or sleep. There was no recent history of recent fall or trauma and fever. Her primary team started oral paracetamol and codeine with limited pain relief. A referral to anaesthesia was made for pain management. We stopped codeine and started oral morphine sulphate $10 \mathrm{mg} 6$ hourly strictly and $10 \mathrm{mg} 4$ hourly for break-through pain. She required morphine sulphate $70-100 \mathrm{mg} /$ day and paracetamol was continued as a regular dose $1 \mathrm{~g} 4$ times a day for control of pain. Non-steroidal anti-inflammatory drugs were withheld as Amniotic fluid Index (AFI) was low, $2.6 \mathrm{~cm}$.

On admission she was afebrile, with white cell count of $21.86 \times 10^{9} / \mathrm{L}$ (reference range 4 - 10) and C-reactive protein level of $285 \mathrm{mg} / \mathrm{L}$ (reference range $0.2-9.1$ ). Repeat MRI showed interval worsening of the pre-sacral lesion with necrosis and pockets of collections, encasing the left internal iliac vessels and rectum, and compressing on the left sciatic and bilateral sacral nerves (Figure 1, Figure 2). The MRI scan was reviewed by another senior radiologist and the diagnosis was revised as presacral abscess. She underwent ultrasound-guided drainage. Cultures grew Parvimonas micra, Peptostreptococcus anaerobius, Porphyromonas gingivalis, Eschericia coli. Her pain improved after drainage and antibiotics (ceftriaxone and metronidazole, later oralized to augmentin). Morphine was eventually stopped. At 32 weeks gestation, she only required paracetamol.

Caesarean section was done electively at 37 weeks. Intraoperatively, there was no pus in the peritoneum or presacral area. The baby weighed $2565 \mathrm{~g}$, with Apgar score of 8 at 1 minute and 9 at 5 minutes. Her baby was hospitalized 5 days for presumptive sepsis. The patient completed 1 week course of antibiotics postoperatively. She declined further scans and outpatient medical appointments for the presacral abscess.

\section{Discussion}

We were presented with a parturient at 25 weeks of pregnancy and due to the 


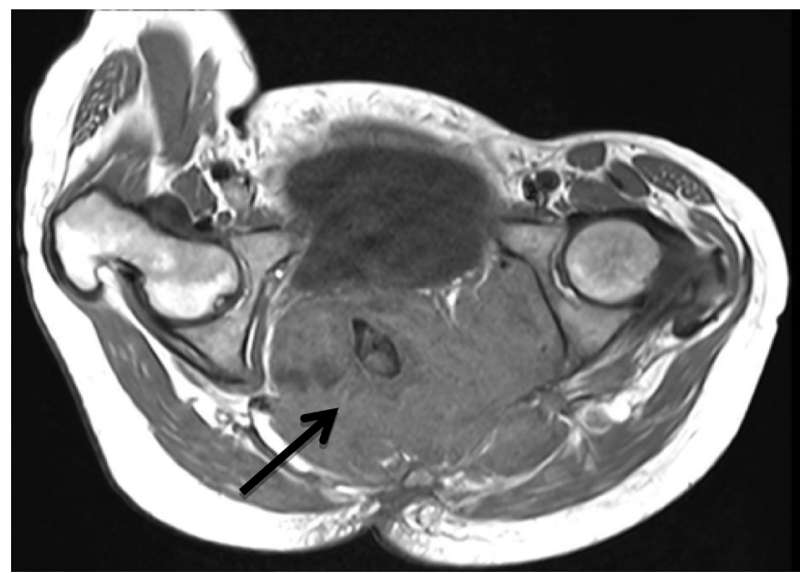

Figure 1. MRI T1-weighted image: Infiltrative lesion encases rectum with likely involvement of rectal wall from 7 o'clock to 11 o'clock.

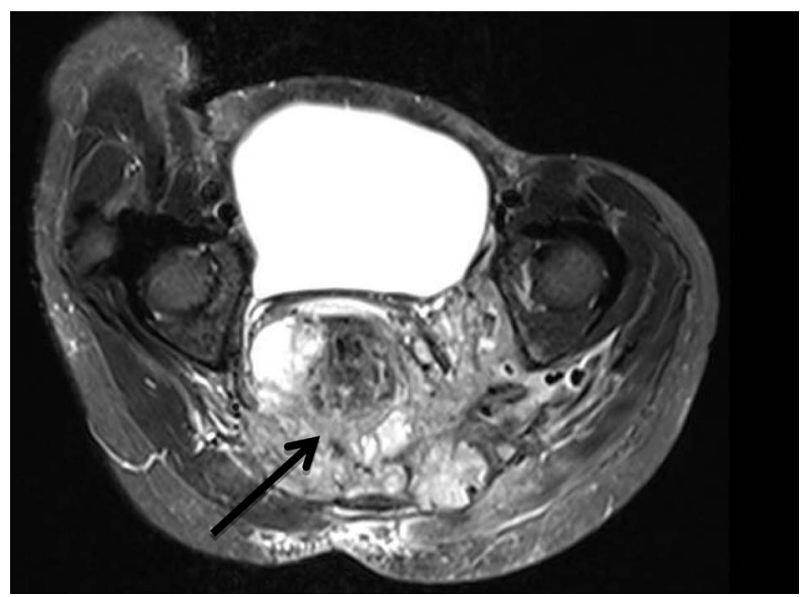

Figure 2. MRI T2-weighted image: Heterogenous infiltrative mass lesion centred at the presacral retro-rectal region, measuring $11.3 \mathrm{~cm} \times 8.3 \mathrm{~cm} \times 10.6 \mathrm{~cm}$ (medial-lateral $\times$ anterior-posterior $\times$ cranial-caudal).

nature of the presacral area, obscure anatomic location and etiological heterogeneity, the diagnosis and management of her pelvic abscess were slightly delayed. Literature regarding the management of such a condition in a parturient is limited due to its rarity. This is the first case report to our knowledge describing the pain management of a parturient with presacral mass.

Presacral tumours are an uncommon entity in adults, where the majority is benign. Clinical diagnosis is challenging and often delayed. Patients are usually found incidentally or have non-specific symptomatology from compression or invasion of pelvic structures by the tumour. This is further compounded by technical difficulties and risks of infection, bleeding, needle track seeding in achieving a biopsy in the presacral location [4]. MRI is recommended in presacral tumour due to its multi-planar capacity and improved soft-tissue resolution. With the addition of endoscopic ultrasound, the extent of the tumour can be delineated and thereby assisting decision on suitability for biopsy and surgical resection [4]. 
Severe pain during pregnancy is challenging to manage in view of considerations for fetal risks and maternal benefits. Inducing delivery or caesarean section in view of fetal immaturity is only a good option after 34 weeks of gestation. However the presence of a presacral tumour may lead to obstructive labour and predispose to life-threatening dystocia.

The first tenet in the medical management of the parturient is to minimize the use of medications and to use non-pharmacological therapies whenever possible. The most critical period for minimizing maternal drug exposure is during organogenesis from the $4^{\text {th }}$ to $10^{\text {th }}$ week of pregnancy. In deciding drug therapy, we should consider any potential for harm to the mother, the fetus, and the course of pregnancy. The most effective and safe drug regimen for treatment of pain during pregnancy remains controversial [5].

Food and Drug Administration (FDA) in the United States, amended its regulations governing the content and format of the labeling for human prescription drug and biological products in the "Pregnancy", "Labor and delivery", and "Nursing mothers" subsections in 2014. The Pregnancy and Lactation Labeling Final Rule (PLLR) requires the removal of the five pregnancy categories of A, B, $\mathrm{C}, \mathrm{D}$, and $\mathrm{X}$ from all drug product labelling, as they were confusing and did not accurately and consistently communicate the differences in degrees of fetal risk, and were often misinterpreted and misused during prescribing. Labelling now requires a summary of the risks of using a drug during pregnancy and lactation, a discussion of the data supporting that summary and relevant information to help health care providers make prescribing decisions and counsel women about the use of drugs during pregnancy and lactation [6].

Paracetamol remains the first line drug treatment for incessant pain in pregnancy and has demonstrated safety at all stages of pregnancy in standard therapeutic doses. It provides similar analgesia as NSAIDS without the anti-prostaglandin or platelet effects. There has been an association with asthma, wheezing and elevated IgE with frequent paracetamol use from 20 - 32 weeks in a subgroup of school aged children [7] [8]. Use of paracetamol may be a marker for infectious or inflammatory disorders, the results of the epidemiology studies may be influenced by confounding by indication, and evidence is inconclusive.

NSAIDS affect renal and cerebral blood flow in the fetus. There are concerns about causation of fetal growth restriction. After 30 weeks of pregnancy, NSAIDs may be associated with bleeding complications, premature closure of the ductus arteriosus and oligohydramnios [9]. Ibuprofen and naproxen have not been linked to congenital defects when taken up to 30 weeks of pregnancy. Low dose aspirin has been used to prevent pre-eclampsia, providing further evidence of its relative safety [10]. NSAIDs should be given in pregnancy only if the maternal benefits outweigh the potential fetal risks, at the lowest effective dose and for the shortest duration possible. In this patient, as the initial ultrasound showed oligohydramnios, naproxen was stopped.

There is few prenatal data on selective COX-2 inhibitors and their use is con- 
traindicated in pregnancy [11] [12].

Most of our knowledge of the effects of chronic opioid use in pregnancy has been extracted from large observational studies of opioid dependent and abusing mothers. There is a need of more studies to better understand their effects on fetus development [13]. Opioid treatment can be harmful for the fetus through both direct effects on the development of the fetus and possible fetal opioid addiction. Dependence and withdrawal symptoms may manifest in the neonate from chronic maternal opioid use, neonatal abstinence syndrome may occur and monitoring is recommended [14]. The minimum effective dose should be used if opioids are needed [15]. In the Boston Collaborative Perinatal Project study, no significant increase was seen overall in either major or minor malformations with codeine, but there was a slight but statistically significant increase in respiratory tract malformations following first trimester use [16]. A large case-control study recently found an association between maternal therapeutic use of opioids in early pregnancy and several congenital heart defects [17].

Opioid rotation should be considered for prolonged opioid usage, as opioids can easily pass through the placenta due to small molecular weight. Switching opioids after prolonged use will allow sufficient pain control with minimal dosage. Opioids should never be discontinued abruptly because the ensuing withdrawal syndrome may produce uterine irritation, miscarriage or premature delivery [18]. Whenever opioid infusions are required, the suggestion is to use opioids with minimal active metabolites [19].

Outcome data following maternal use of gabapentin and pregabalin during pregnancy is limited [20].

The use of regional techniques, such as an epidural was considered. However the epidural catheter would present a serious risk of infection if maintained for a prolonged period of time. Due to the uncertainty in diagnosis and management of the presacral mass, we felt an epidural was not a viable management option. Other nerve blocks and plexus blocks such as superior or inferior hypogastric plexus were considered but deemed unsafe as it would involve injection near or at the presacral mass itself.

\section{Conclusion}

This case highlighted the importance for high clinical acumen and the need for multidisciplinary approach of care to parturients with severe pain. Early referral to anaesthetists and other specialties improves the quality of care in pregnancy. Opioids for pain management in parturients is a useful option for improving fetomaternal prognosis.

\section{References}

[1] Díaz, R.R. and Rivera, A.L. (2012) Management of Non-Obstetric Pain during Pregnancy. Review Article. Colombian Journal of Anesthesiology, 40, 213-223. https://doi.org/10.1016/j.rcae.2012.05.005

[2] Hassan, I. and Wietfeldt, E.D. (2009) Presacral Tumors: Diagnosis and Manage- 
ment. Clinics Colon and Rectal Surgery, 22, 84-93.

https://doi.org/10.1055/s-0029-1223839

[3] Mazreku, A., Karaj, A., Avdia, I. and Bilali, S. (2010) The Presentation and Management of Presacral Tumors. Acta Chirurgica Iugoslavica, 57, 55-59. https://doi.org/10.2298/ACI1002055M

[4] Wolpert, A., Beer-Gabel, M., Lifschitz, O. and Zbar, A.P. (2002) The Management of Presacral Masses in the Adult. Techniques in Coloproctology, 6, 43-49. https://doi.org/10.1007/s101510200008

[5] Rathmell, J.P., Viscomi, C.M. and Ashburn, M.A. (1997) Management of Nonobstetric Pain during Pregnancy and Lactation. Anesthesia and Analgesia, 85, 1074-1087.

[6] FDA (2014) Content and Format of Labeling for Human Prescription Drug and Biological Products; Requirements for Pregnancy and Lactation Labeling. Federal Register, 79, 72063-72103.

[7] Shaheen, S.O., Newson, R.B., Henderson, A.J., et al. (2005) Prenatal Paracetamol Exposure and Risk of Asthma and Elevated Immunoglobulin E in Childhood. Clinical and Experimental Allergy, 35, 18-25. https://doi.org/10.1111/j.1365-2222.2005.02151.x

[8] Eyers, S., Weatherall, M., Jefferies, S. and Beasly, R. (2011) Paracetamol in Pregnancy and the Risk of Wheezing in Offspring: A Systematic Review and Meta-Analysis. Clinical and Experimental Allergy, 41, 482-489. https://doi.org/10.1111/j.1365-2222.2010.03691.x

[9] Koren, G., Florescu, A., Costei, A.M., Boskovic, R. and Moretti, M.E. (2006) Nonsteroidal Anti-Inflammatory Drugs during Third Trimester and the Risk of Premature Closure of the Ductus Arteriosus: A Meta-Analysis. Annals of Pharmacotherapy, 40, 824-829. https://doi.org/10.1345/aph.1G428

[10] Askie, L.M., Duley, L., Henderson-Smart. D.J. and Stewart, L.A. (2007) Antiplatelet Agents for Prevention of Pre-Eclampsia: A Meta-Analysis of Individual Patient Data. Lancet, 369, 1791-1798. http://dx.doi.org/10.1016/S0140-6736(07)60712-0

[11] Ostensen, M., Khamashta, M., Lockshin, M., Parke, A., Brucato, A., Carp, H., et al. (2006) Anti-Inflammatory and Immunosuppressive Drugs and Reproduction. Arthritis Research \& Therapy, 8, 209-334. https://doi.org/10.1186/ar1957

[12] Takahashi, Y., Roman, C., Chemtob, S., Tse, M.M., Lin, E., Heymann, M.A., et al. (2000) Cyclooxygenase-2 Inhibitors Constrict the Fetal Lamb Ductus Arteriosus both in Vitro and in Vivo. American Journal of Physiology. Regulatory, Integrative and Comparative Physiology, 278, R1496-R1505.

[13] Coluzzi, F., Valensise, H., Sacco, M. and Allegri, M. (2014) Chronic Pain Management in Pregnancy and Lactation. Minerva Anestesiologica, 80, 211-224.

[14] Hudak, M.L., Tan, R.C., Committee On Drugs, et al. (2012) Neonatal Drug Withdrawal. Pediatrics, 129, e540-e560. https://doi.org/10.1542/peds.2011-3212

[15] Chou, R., Fanciullo, G.J., Fine, P.G., et al. (2009) Clinical Guidelines for the Use of Chronic Opioid Therapy in Chronic Noncancer Pain. Journal of Pain, 10, 113-130.

[16] Heinomen, O.P., Slone, S. and Shapiro, S. (1977) Birth Defects and Drugs in Pregnancy. Publishing Science Group, Littleton.

[17] Broussard, C.S., Rasmussen, S.A., Reefhuis, J., Friedman, J.M., Jann, M.W., Riehle-Colarusso, T., et al. (2011) Maternal Treatment with Opioid Analgesics and Risk for Birth Defects. American Journal of Obstetrics \& Gynecology, 204, 314.e1-e11. 
[18] American Society of Anesthesiologists Task Force on Chronic Pain Management, American Society of Regional Anesthesia and Pain Medicine (2010) Practice Guidelines for Chronic Pain Management: An Updated Report by the American Society of Anesthesiologists Task Force on Chronic Pain Management and the American Society of Regional Anesthesia and Pain Medicine. Anesthesiology, 112, 810-833. https://doi.org/10.1097/ALN.0b013e3181c43103

[19] Collins, L.R., Hall, R.W., Dajani, N.K., Wendel, P.J., Lowery, C.L. and Kay, H.H. (2005) Prolonged Morphine Exposure in Utero Causes Fetal and Placental Vasoconstriction: A Case Report. The Journal of Maternal-Fetal \& Neonatal Medicine, 17, 417-421. https://doi.org/10.1080/14767050500123996

[20] Veiby, G., Daltveit, A.K., Engelsen, B.A. and Gilhus, N.E. (2014) Fetal Growth Restriction and Birth Defects with Newer and Older Antiepileptic Drugs during Pregnancy. Journal of Neurology, 261, 579-588.

https://doi.org/10.1007/s00415-013-7239-x 